\title{
The Impact of Water Exchange Rate and Treatment Processes on Water- Borne Hormones in Recirculation Aquaculture Systems Containing Sexually Maturing Atlantic Salmon Salmo salar
}

\section{Christopher Good ${ }^{1 *}$, John Davidson', Ryan L Earley², Elizabeth Lee ${ }^{2}$ and Steven Summerfelt ${ }^{1}$}

${ }^{1}$ The Conservation Fund's Freshwater Institute, 1098 Turner Road, Shepherdstown, West Virginia 25443, USA

${ }^{2}$ Department of Biological Sciences, University of Alabama, 300 Hackberry Lane, Tuscaloosa 35401, Alabama

\begin{abstract}
A controlled seven-month study was conducted in six replicated water recirculation aquaculture systems (WRAS) to assess post-smolt Atlantic salmon (Salmo salar) performance in relation to WRAS water exchange rate. Unexpectedly high numbers of precocious sexually mature fish were observed in all WRAS toward the end of the study period; therefore, a separate investigation was conducted to quantify the levels of water-borne hormones (cortisol $(C)$, testosterone $(T)$, 11-ketotestosterone (11-KT), progesterone $(P)$, and estradiol $(E 2)$ ) to determine the impact of WRAS exchange rate, as well as transit through the unit processes, on soluble hormone concentrations. Triplicate water samples were collected at three separate sites in each of the six WRAS: pre-unit processes, post-unit processes, and at the makeup water influent. Water samples were concentrated and separate quantifications were carried out for each target hormone using enzyme immunoassay kits. Results indicated that among the hormones examined, only T was associated with higher concentrations in low exchange WRAS compared to high exchange WRAS. Water passage through the unit processes was associated with a significant reduction in concentration of 11-KT, in both high and low exchange WRAS. Water-borne concentrations of T, 11-KT, and E2 were significantly higher than influent makeup water; the majority of $\mathrm{C}$ and $\mathrm{P}$ concentrations were not significantly different between WRAS and makeup water samples. No significant differences were noted in the prevalence of apparently sexually mature fish or gonadosomatic indices in either sex between treatments, except a significantly higher prevalence of apparently mature female fish in low exchange WRAS. Overall, these findings suggest that, under the conditions of this study, C, P, E2, and 11-KT do not accumulate in lower exchange WRAS, and that, aside from 11-KT, the WRAS unit processes do not impact hormone concentration. Furthermore, the observed precocious sexual maturation was mostly unrelated to WRAS exchange rate.
\end{abstract}

Keywords: Recirculation aquaculture; Water-borne hormones; Atlantic salmon

\section{Introduction}

The development of sexual maturation in Atlantic salmon (Salmo salar) is a highly flexible process $[1,2]$, and can be influenced by numerous environmental cues and host factors. Previous research has identified the contributions of, among other things, photoperiod [2-5], water temperature [6,7], feed intake [8], nutrition [9], lipid reserves [10], growth rate [11,12], and stock genetics [13], on the timing of sexual maturation in Atlantic salmon. Wild populations typically mature as adults in seawater [14], although the occurrence of very early maturing males (i.e. precocious parr) is well known in wild populations $[15,16]$, and in the salmon farming industry both precocious parr and early maturing post-smolt males ('jacks' or 'grilse') occur [17]. Precocious parr are relatively easy to identify and are typically culled prior to sea transfer; however, early maturing post-smolts are not distinguishable at this point in the production cycle, and go on to cause difficulties for farmers during sea-cage growout. Due to decreased growth and feed conversion efficiency [18] and reduced product quality [19], grilsing represents a major source of economic loss for farmers [18,20]. Current strategies for reducing post-smolt maturation in the salmon farming industry include photoperiod control [5], selective breeding for late maturation [21], and inducing triploidy during egg incubation [22].

Putative environmental issues associated with open sea cage aquaculture, including fish escapes [23,24] and subsequent genetic introgression with wild populations $[25,26]$, pollution of coastal waters [27,28], spread of disease to wild populations [29,30], and environmental dissemination of antibiotics and chemotherapeutants [31], have influenced the development of alternative approaches to salmon farming, such as land-based closed containment facilities utilizing water reuse aquaculture system (WRAS) technologies. Growing Atlantic salmon to market size in fresh- or partially saline water in land-based closed containment systems is, at present, a frontier in agriculture. Numerous elements of closed containment salmon production still need to be fully characterized or refined through scientific research, including developing a better understanding of maturation cues in the water recirculation environment and husbandry approaches to minimize precocious sexual development. Among other things, there is potential for various substances to accumulate in WRAS as water exchange rate decreases (i.e., the rate of new or 'makeup' water entering the system is reduced) [32-34]. Whether the accumulated substances, such as hormones, in recirculating water influence precocious maturation requires investigation.

Studies on the control of sexual maturation in farmed fishes have been thoroughly reviewed [35], and further research is required

*Corresponding author: Christopher Good, The Conservation Fund's Freshwater Institute, 1098 Turner Road, Shepherdstown, West Virginia 25443, USA, Tel: 304876-2815-279; Fax: 304-870-2208; E-mail: c.good@freshwaterinstitute.org

Received March 25, 2014; Accepted August 08, 2014; Published August 16 2014

Citation: Good C, Davidson J, Earley RL, Lee E, Summerfelt S (2014) The Impact of Water Exchange Rate and Treatment Processes on Water-Borne Hormones in Recirculation Aquaculture Systems Containing Sexually Maturing Atlantic Salmon Salmo salar. J Aquac Res Development 5: 260. doi:10.4172/2155-9546.1000260

Copyright: (c) 2014 The Conservation Fund. This is an open-access article distributed under the terms of the Creative Commons Attribution License, which permits unrestricted use, distribution, and reproduction in any medium, provided the original author and source are credited. 
Citation: Good C, Davidson J, Earley RL, Lee E, Summerfelt S (2014) The Impact of Water Exchange Rate and Treatment Processes on Water-Borne Hormones in Recirculation Aquaculture Systems Containing Sexually Maturing Atlantic Salmon Salmo salar. J Aquac Res Development 5: 260. doi:10.4172/2155-9546.1000260

Page 2 of 7

to expand our knowledge in this area. Newer approaches utilizing non-invasive methods to quantify hormones in water samples via radioimmunoassay (RIA) [36] and enzyme immunoassay (EIA) [37,38] techniques have facilitated research in this area, and have been validated in several commercially important fish species such as rainbow trout (Oncorhynchus mykiss) [36]. Because fish release steroid hormones into the surrounding water, either in conjugated (sulfonated or glucuronidated) forms in the urine and feces [39] or in unconjugated 'free' form through the gills $[40,41]$, there is a potential for these compounds to gradually increase in concentration in recirculated water. Whether physiologically relevant hormones actually accumulate in WRAS, and whether this accumulation can influence maturation, has not been adequately assessed in previously published research.

During an on-site long-term study examining Atlantic salmon growout performance in freshwater WRAS, it was observed that a significant proportion of fish (both male and female) were demonstrating morphological characteristics of precocious sexual maturation beginning approximately 18 months post-hatch. These observations provided opportunity for a separate study, presented here, to determine whether physiologically relevant hormones were accumulating in the WRAS, and whether concentrations of water-borne hormones were associated with different water exchange rates and relative proportions of early maturing fish. A secondary objective was to determine the impact, if any, on water-borne hormone concentration following passage through the WRAS treatment processes, i.e. the fluidized sand biofilters, degassing towers, and low-head oxygenators (LHOs).

The specific hormones quantified in this study were the androgens testosterone (T) and 11-ketotestosterone (11-KT); estradiol (E2); progesterone $(\mathrm{P})$; and cortisol (traditionally abbreviated as $\mathrm{F}$, but for the purpose of clarity represented by $\mathrm{C}$ in this paper). In general, 11$\mathrm{KT}$ ( $\mathrm{a}$ derivative of $\mathrm{T}$ ) is the major androgen produced by the testes of teleost fish [35], and likely triggers the onset of male sexual maturation in a variety of fish species [42-45]; rising E2 levels are associated

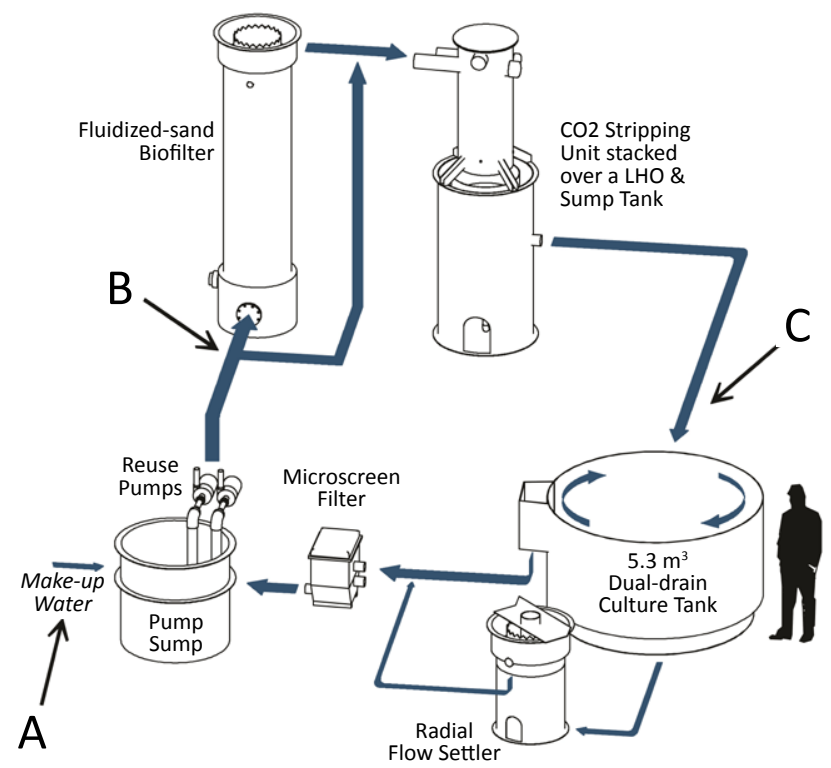

Figure 1: Process flow diagram for an individual experimental water recirculating aquaculture system (WRAS); locations (A-C) for water sample collections are indicated. with commencement of secondary oocyte growth in Atlantic salmon females [46,47]; and progesterone, although not considered to be an active fish steroid [48], can be enzymatically converted to E2, C, and $\mathrm{T}$, and is therefore of interest for the purposes of this study. Likewise, although not considered a sex hormone, $\mathrm{C}$ can influence physiological processes such as sperm motility [48] and likely has an impact on overall maturation in fish populations. The above hormones were therefore selected based on their physiological influences, and on the current availability of non-invasive techniques for hormone quantification from water samples.

\section{Materials and Methods}

\section{Experimental set-up and research animals}

A controlled seven-month study was conducted onsite in six replicated WRAS to assess post-smolt Atlantic salmon growout performance in fresh water relative to the level of system flushing. The experimental WRAS have been described in detail previously [49-51]; the components of an individual system are illustrated in Figure 1. Briefly, each WRAS consisted of the following: fluidized-sand biofilter, $\mathrm{CO}_{2}$ stripping column, $\mathrm{LHO}$, circular dual-drain culture tank $\left(5.3 \mathrm{~m}^{3}\right)$, radial flow settler, microscreen drum filter $(60 \mu \mathrm{m})$, heat exchanger, and a $1 \mathrm{HP}$ centrifugal pump. Total system volume was $9.5 \mathrm{~m}^{3}$ with a recirculation rate of $380 \mathrm{~L} / \mathrm{min}(100 \mathrm{gpm})$.

Post-smolt Atlantic salmon, initially acquired as eyed eggs from a commercial producer, were maintained under experimental conditions for seven months at a density range of $35 \mathrm{~kg} / \mathrm{m}^{3}$ to $92 \mathrm{~kg} / \mathrm{m}^{3}$. Initially, 210 salmon were stocked into each WRAS and allowed to acclimate for a period of 52 days. At the onset of the experiment, fish were 426 day post-hatch and weighed $931 \pm 11 \mathrm{~g}$ on average across all WRAS. Experimental conditions were as follows: three WRAS received a high makeup water exchange rate (2.6\%), while three systems received a low $0.26 \%$ exchange. Exchange rates were set on a flow basis (i.e., for high exchange (2.6\%) WRAS, the $380 \mathrm{~L} / \mathrm{min}(100 \mathrm{gpm})$ system recirculation flow contained $9.8 \mathrm{~L} / \mathrm{min}(2.6 \mathrm{gpm})$ of makeup water), and high and low exchange treatments were randomly allocated among the six WRAS. All WRAS makeup water originated from a groundwater spring source with approximately 4,540 L/min (1200 gpm) flow. Mean feed loadings of 0.13 and $1.3 \mathrm{~kg} /$ day per $\mathrm{m}^{3} /$ day of makeup water flow, and hydraulic retention times of 0.7 and 7.0 days, were maintained for the high and low exchange treatments, respectively. Standardized feeding charts were employed to determine amounts of feed administered, supplemented by observations of feeding activity and wasted feed. A constant photoperiod (i.e. continuous 24 hour lighting) was provided, and all tanks were administered feed once every 2 hours using automated feeders (T-drum 2000CE, Arvo-Tec, Finland).

Beginning approximately midway through the study period, it was observed that a significant proportion of fish in each of the treatment groups was exhibiting obvious signs of precocious sexual maturation (e.g. pronounced kype development in males, and visible ovipositor in females). Because prevalent sexual maturation is unexpected in Atlantic salmon populations of this age (at the time of study's end, fish age was only 637 days post-hatch), it was hypothesized that environmental factors, such as the freshwater conditions, water temperature, constant photoperiod, or accumulating steroid hormones, could have contributed to the observed early-onset sexual maturation. The possibility of steroid hormone accumulation was testable given the high vs. low exchange rate experimental conditions; therefore, a sub-study was conducted to assess levels of specific water-borne hormones in the WRAS water, to determine whether concentrations of target hormones were related to 


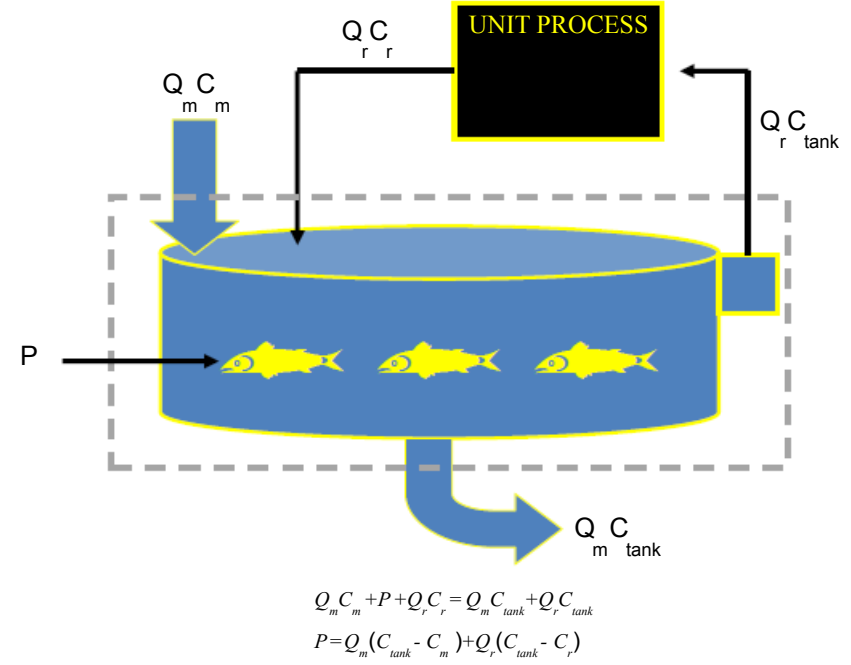

Figure 2: A quasi-steady state mass balance about the water recirculating system includes water flow rates $(Q$, in $L /$ day) plus inlet and outlet concentrations $(C$, in mass/L) and the production rate of hormone ( $P$, in mass/day). Subscripts: $\mathrm{m}=$ makeup water; $\mathrm{r}=$ recirculating water; tank=culture tank.

system exchange rate, and to correlate these findings with observations of fish maturation in each of the treatment groups. An additional area of investigation was to determine whether concentrations of waterborne hormones were affected by passage through the water treatment processes.

\section{Water sampling and hormones analyses}

Towards the end of the study period, three $250 \mathrm{~mL}$ water samples were collected from each WRAS from each of the following sampling locations: (A) makeup water influent, (B) pre-unit processes, and (C) post-unit processes (Figure 1) (note that for dissolved constituents such as hormones, sampling at the pre-unit processes (B) and post-unit processes $(\mathrm{C})$ locations is equivalent to sampling at the culture tank outlet and culture tank inlet, respectively). The water samples were immediately placed on dry ice and shipped overnight to the University of Alabama for analyses, using enzyme-immunoassay (EIA) kits (Cayman Chemicals Inc., Ann Arbor, Michigan, USA) for T, 11-KT, $\mathrm{C}, \mathrm{P}$, and $\mathrm{E} 2$.

Upon arrival, water samples were transferred to $4^{\circ} \mathrm{C}$ refrigeration and allowed to thaw overnight, after which they were filtered through Whatman Grade 1 filter paper (GE Healthcare Life Sciences, Piscataway, New Jersey, USA) into $400 \mathrm{~mL}$ glass beakers pre-cleaned with 95\% ethanol and distilled water. Waters Sep-Pak C18 columns (Milford, Massachusetts, USA) were primed with $2 \times 2 \mathrm{~mL}$ HPLC grade methanol followed by $2 \times 2 \mathrm{~mL}$ distilled water, with the last $0.5 \mathrm{~mL}$ of distilled water retained to keep the columns moist. Tygon tubing was pre-cleaned with $100 \%$ ethanol and rinsed with distilled water, fitted to the columns on a vacuum manifold, and the opposite tubing ends were placed into the $400 \mathrm{~mL}$ glass beakers containing the filtered water samples. The tubing material used was formulation 2275 , which does not adsorb hormones or leach compounds mimicking hormones into the water. The sample water was then vacuumed through the C18 columns to trap the steroid hormones, after which the columns were stored dry at $-20^{\circ} \mathrm{C}$. When ready to process, columns were thawed at room temperature and, to remove any lingering salts, $2 \mathrm{~mL}$ of distilled water was passed over the columns. The 'free' hormone fraction was eluted with $2 \times 2 \mathrm{~mL}$ ethyl acetate into $13 \times 100 \mathrm{~mm}$ borosilicate vials. To elute the conjugated (i.e. sulphated, glucuronidated) hormone fractions, $2 \times 2 \mathrm{~mL}$ methanol was passed over the columns into new $13 \times 100 \mathrm{~mm}$ borosilicate vials. All samples were then dried under a gentle stream $(\sim$ 7 bar) of ultrapure nitrogen at $37^{\circ} \mathrm{C}$ in a water bath. Dried conjugated samples were capped and stored at $-20^{\circ} \mathrm{C}$, while dried free samples were stored at $-20^{\circ} \mathrm{C}$ overnight and then resuspended (vortexing for $20 \mathrm{~min}$ ) in $500 \mu \mathrm{L}$ of $5 \%$ EtOH: 95\% EIA buffer (Cayman Chemicals, Inc.). Kit validations were run for each target hormone, by collecting $100 \mu \mathrm{L}$ from each of the 54 samples into a $5.4 \mathrm{~mL}$ pool and then carrying out serial dilutions (using EIA buffer) from 1:1 until 1:128. Serial dilution curves were generated for each hormone to determine the optimum dilution at which to assay hormone levels, and based on these determinations $\mathrm{T}$ and 11-KT were diluted 1:16, and $\mathrm{C}, \mathrm{P}$, and $\mathrm{E} 2$ were diluted 1:8, For each hormone, the appropriate volume from each water sample's original resuspension was added to the corresponding volume of EIA buffer to achieve the desired dilutions, followed by vortexing. Enzymeimmunoassays were then carried out according to kit instructions to quantify actual hormone concentrations. Assessing parallelism between curves (concentration vs. absorbance) generated from serially diluted $S$. salar pools and the kit standard curves validated the assays. $S$. salar serial dilution curves were parallel to the kit standard curves for all hormones (comparison of slopes test (Zar, 1996); $\mathrm{C}: \mathrm{t}_{12}=0.0, \mathrm{p}=0.97$; 11-KT: $\mathrm{t}_{12}=-0.03, \mathrm{p}=0.98 ; \mathrm{T}: \mathrm{t}_{12}=0.0, \mathrm{p}=1.0 ; \mathrm{E} 2: \mathrm{t}_{12}=0.04, \mathrm{p}=0.97 ; \mathrm{P}$ : $\mathrm{t}_{12}=0.04, \mathrm{p}=0.97$ ). Each hormone was assayed on 3, 96-well plates (one serial dilution plate; two experimental sample plates), except for E2 and $\mathrm{P}$, for which assays were conducted on two plates (one plate with serial dilution plus experimental samples; one plate with only experimental samples). On each plate, a pooled $S$. salar control was assayed in the first and last two sample wells. Intra-assay coefficients of variation for these controls were: $\mathrm{C}$ (plate 1:3.9\%, plate $2: 3.0 \%$, plate $3: 4.2 \%$ ); $11-\mathrm{KT}$ (6.7\%, 10.3\%, $12.9 \%)$; T $(2.6 \%, 9.5 \%, 7.7 \%)$; E2 (6.4\%, $4.5 \%)$; P (8.7\%, $14.8 \%)$. Inter-assay coefficients of variation were: C (14.2\%), 11-KT (11.4\%), T (7.6\%), E2 (12.3\%), P (12.1\%).

\section{Mass balance for hormone production in WRAS}

A mass balance was developed to estimate production rates of hormone when quasi-steady state conditions are assumed (Figure 2). The production of hormone $(P$, in $\mu \mathrm{g} /$ day $)$ was estimated from water flows $\left(Q_{\mathrm{m}}=\right.$ makeup water flow; $Q_{\mathrm{r}}=$ recirculating water flow) and hormone concentrations $\left(C_{\text {tank }}=\right.$ concentration exiting culture tank; $C_{\mathrm{m}}=$ concentration in makeup water; and $C_{\mathrm{r}}=$ concentration returning to the culture tank) using the following equation:

$$
P=Q_{m}\left(C_{\text {tank }}-C_{m}\right)+Q_{r}\left(C_{\text {tank }}-C_{r}\right)
$$

This mass balance was applied only for hormones demonstrating a statistically significant difference $(\mathrm{p}<0.05)$ in concentration between pre- and post-unit processes samples. In addition, hormone removal efficiency across the unit processes was calculated from the difference in inlet and outlet hormone concentrations divided by the inlet hormone concentration when expressed as a percent.

If no significant difference in hormone concentration existed between the pre- and post-unit processes locations (indicating that production and removal rates were not detected), then these inlet and outlet concentrations were averaged and the mass balance was simplified to calculate a net rate that the hormone is produced across the system:

$$
P=Q_{m}\left(C_{\text {tank }}-C_{r}\right)
$$


Citation: Good C, Davidson J, Earley RL, Lee E, Summerfelt S (2014) The Impact of Water Exchange Rate and Treatment Processes on Water-Borne Hormones in Recirculation Aquaculture Systems Containing Sexually Maturing Atlantic Salmon Salmo salar. J Aquac Res Development 5: 260. doi:10.4172/2155-9546.1000260

Page 4 of 7

\section{Salmon maturity assessments}

The majority of the study's fish population was needed for post-study product quality assessments, and therefore a comprehensive examination of sexual maturity (i.e. lethal sampling to obtain gonadosomatic indices for all fish) at study's end was not possible. However, two reducedscale salmon maturity assessments were carried out at study's end: (i) 8 fish per WRAS were randomly sampled, euthanized with $200 \mathrm{mg} / \mathrm{L}$ tricaine methanesulfonate (MS-222), measured for whole body mass and gonad mass to obtain gonadosomatic indices; and (ii) during poststudy transfer of fish to a separate rearing area, all fish $(n=357)$ were visually assessed for morphological changes indicating sexual maturity, namely a prominent kype for males and the presence of an ovipositor for females. For the latter assessment, in order to compute estimates of percentage sexually mature males and females in each treatment group, a 50:50 male:female ratio for the study population was assumed.

\section{Statistical analyses}

To compare mean hormone concentrations between treatment groups and sampling locations, paired t-tests were performed for all possible pairwise comparisons, with differences reported as significant $(\mathrm{p}<0.05)$ or trending toward significance $(0.10 \geq \mathrm{p} \geq 0.05)$. To compare percentage mature fish based on secondary sexual characteristics, the percentages of mature males and females within each RAS were first arcsine-transformed prior to analyses using two-sample t-tests; t-tests were also used to compare male and female gonadosomatic indices between treatment groups [52]. All statistical analyses were performed using STATA v.9 software (StataCorp LP, College Station, Texas, USA).

\section{Results}

\section{Fish population characteristics at the time of water sampling}

The salmon were 615 days post-hatch in age at the time of WRAS water sampling, with fish weighing $2.768 \pm 0.049 \mathrm{~kg}$ and $2.727 \pm 0.032 \mathrm{~kg}$ in the high and low exchange treatment groups, respectively $(\mathrm{p}=0.264$; no significant difference in fish weight). Gonadosomatic indices from a random sample of 8 fish per WRAS were, for males, $6.79 \pm 0.30 \%$ and $5.94 \pm 0.79 \%(\mathrm{p}=0.185)$ in the high and low exchange treatment groups, respectively. Female gonadosomatic indices were $3.06 \pm 1.38 \%$ and $5.24 \pm 4.97 \%(\mathrm{p}=0.347)$ in the high and low exchange treatment groups, respectively (Table 1). Further visual assessments of salmon populations at study's end, during transfer of the fish to a separate rearing area, indicated mature male prevalences of $75.6 \pm 13.7 \%$ and $67.8 \pm 8.07 \%(\mathrm{p}=0.221)$ in the high and low exchange treatment groups, respectively, and mature female prevalence estimates of $11.3 \pm 3.27 \%$ and $3.23 \pm 1.47 \%(\mathrm{p}=0.056)$ in the high and low exchange treatment groups, respectively (Table 1 ).

\section{Assays quantifying water-borne hormones}

Tables 2 and 3 summarize the concentrations of each target hormone and their relative differences between water exchange treatment groups and sample collection locations. Only 11-KT demonstrated significant $(\mathrm{p}<0.05)$ measurable production across the culture tank and removal across the unit processes; 11-KT removal efficiencies for the WRAS unit processes were $32 \%$ and $34 \%$ for each pass at the low and high flushing treatments, respectively (Table 4). The 11-KT mass balance also suggested that 0.31 and $0.36 \mu$ g of the hormone was produced daily for every kilogram of salmon biomass in the low and high flushing systems treatments, respectively. Water-borne concentrations of T, 11-KT, and E2 tended to be significantly higher in WRAS compared to the makeup water, whereas $\mathrm{C}$ and $\mathrm{P}$ tended to be similar in concentration between WRAS and makeup water samples. Thus, these findings suggest that $\mathrm{T}$, 11-KT, and E2 were being quantifiably produced by the fish, although there were insufficient differences in T and E2 concentrations across the culture tank to accurately estimate their tank production and unit processes removal rates. Only $\mathrm{T}$ demonstrated a tendency $(\mathrm{p}<0.10)$ to accumulate as the WRAS flushing rate was reduced.

\begin{tabular}{|c|c|c|c|}
\hline & \multirow{2}{*}{ Sex } & \multicolumn{2}{|c|}{ WRAS } \\
\hline & & High exchange & Low exchange \\
\hline \multirow{2}{*}{$\begin{array}{l}\text { Percent mature, based on observation of secondary sexual } \\
\text { characteristics }{ }^{1}(n=357)\end{array}$} & Male & $75.6 \pm 13.7^{\mathrm{a}}$ & $67.8 \pm 8.07^{a}$ \\
\hline & Female & $11.3 \pm 3.27^{\mathrm{a}}$ & $3.23 \pm 1.47^{\mathrm{b}}$ \\
\hline \multirow{2}{*}{ Gonadosomatic index $(n=24)$} & Male & $6.79 \pm 0.30^{\mathrm{a}}$ & $5.94 \pm 0.79^{a}$ \\
\hline & Female & $3.06 \pm 1.38^{\mathrm{a}}$ & $5.24 \pm 4.97^{a}$ \\
\hline
\end{tabular}

${ }^{1}$ Secondary sexual characteristics: males=prominent kype; females=ovipositor. Percentage mature based on final fish numbers with assumed $50: 50$ male:female ratio. Different letters between treatments for each sex indicate differences trending toward statistical significance $(0.10 \geq p \geq 0.05)$.

Table 1: End-of-study fish maturation assessments, summarizing prevalence of qualitatively determined sexually mature individuals and quantitatively determined gonadosomatic indices for each sex within high and low exchange WRAS treatment groups.

\begin{tabular}{|c|c|c|c|c|}
\hline \multirow[b]{2}{*}{ Hormone } & \multirow[b]{2}{*}{ WRAS ( $n=3)$ exchange rate } & \multicolumn{3}{|c|}{ Water sample location } \\
\hline & & Makeup influent (A) & Pre-unit processes (B) & Post-unit processes (C) \\
\hline \multirow{2}{*}{ Cortisol } & High & $555.8 \pm 186.6^{a}$ & $575.6 \pm 121.6 a$ & $545.1 \pm 214.3 a$ \\
\hline & Low & $319.7 \pm 181.0^{\mathrm{a}}$ & $448.6 \pm 191.6^{a}$ & $448.6 \pm 176.4^{a}$ \\
\hline \multirow{2}{*}{ Testosterone } & High & $123.7 \pm 7.313^{a}$ & $518.7 \pm 118.0 b^{d}$ & $443.7 \pm 86.32^{\mathrm{b}}$ \\
\hline & Low & $124.0 \pm 45.24^{\mathrm{a}}$ & $768.4 \pm 88.88^{c}$ & $758.5 \pm 155.5^{\mathrm{cd}}$ \\
\hline \multirow{2}{*}{ 11-ketotestosterone } & High & $4.783 \pm 0.390^{\mathrm{a}}$ & $194.5 \pm 21.19^{c}$ & $127.9 \pm 11.08^{b}$ \\
\hline & Low & $4.526 \pm 1.008^{\mathrm{a}}$ & $183.0 \pm 17.73^{c}$ & $124.7 \pm 11.90^{\mathrm{b}}$ \\
\hline \multirow{2}{*}{ Progesterone } & High & $1134 \pm 63.43^{a}$ & $1422 \pm 121.6^{b}$ & $1699 \pm 420.1^{\mathrm{ab}}$ \\
\hline & Low & $1339 \pm 491.0 \mathrm{a}^{\mathrm{b}}$ & $1551 \pm 263.5 \mathrm{a}^{\mathrm{b}}$ & $1742 \pm 286.4^{\mathrm{ab}}$ \\
\hline \multirow{2}{*}{ Estradiol } & High & $39.55 \pm 6.341^{\mathrm{a}}$ & $168.7 \pm 61.80^{\mathrm{b}}$ & $168.8 \pm 66.25^{b}$ \\
\hline & Low & $38.92 \pm 25.06^{\mathrm{a}}$ & $223.5 \pm 28.53^{b}$ & $239.8 \pm 20.69^{b}$ \\
\hline
\end{tabular}

Table 2: Hormone levels in water collected from makeup influent $(A)$ and pre- $(B)$ and post- $(C)$ unit processes sample locations. Values reported are mean $( \pm$ standard error) hormone concentrations (pg/250mL) for water samples in each treatment group, adjusted for dilution factor and resuspension volume. Different superscript letters within each hormone summary represent statistical trends $(0.10 \geq p \geq 0.05)$ or significant differences $(p<0.05)$ between quantified hormone levels (Table 3 summarizes relationships with $\mathrm{p} \leq 0.10)$. 
Citation: Good C, Davidson J, Earley RL, Lee E, Summerfelt S (2014) The Impact of Water Exchange Rate and Treatment Processes on Water-Borne Hormones in Recirculation Aquaculture Systems Containing Sexually Maturing Atlantic Salmon Salmo salar. J Aquac Res Development 5: 260. doi:10.4172/2155-9546.1000260

Page 5 of 7

\begin{tabular}{|c|c|c|}
\hline Hormone & Relationship determined between measured hormone concentrations & p-value \\
\hline \multirow{6}{*}{ Testosterone } & Pre-unit processes>makeup (high exchange) & 0.0144 \\
\hline & Post-unit processes>makeup (high exchange) & 0.0105 \\
\hline & High exchange pre-unit processes $<$ low exchange pre-unit processes & 0.0831 \\
\hline & High exchange post-unit processes $<$ low exchange post-post unit processes & 0.0758 \\
\hline & Pre-unit processes>makeup (low exchange) & 0.0015 \\
\hline & Post-unit processes>makeup (low exchange) & 0.0086 \\
\hline \multirow{6}{*}{$11-\mathrm{KT}$} & Pre-unit processes>makeup (high exchange) & 0.0004 \\
\hline & Post-unit processes>makeup (high exchange) & 0.0002 \\
\hline & Pre-unit processes>post-unit processes (high exchange) & 0.0248 \\
\hline & Pre-unit processes>makeup (low exchange) & 0.0003 \\
\hline & Post-unit processes>makeup (low exchange) & 0.0003 \\
\hline & Pre-unit processes>post-unit processes (low exchange) & 0.0262 \\
\hline Progesterone & Pre-unit processes>makeup (high exchange) & 0.0516 \\
\hline \multirow{4}{*}{ Estradiol } & Pre-unit processes>makeup (high exchange) & 0.0530 \\
\hline & Post-unit processes>makeup (high exchange) & 0.0620 \\
\hline & Pre-unit processes>makeup (low exchange) & 0.0041 \\
\hline & Post-unit processes>makeup (low exchange) & 0.0017 \\
\hline
\end{tabular}

Table 3: Selected water sample comparisons demonstrating trends $(0.10 \geq p \geq 0.05)$ and statistically significant differences ( $<<0.05)$ for quantified hormone concentrations.

\begin{tabular}{|c|c|c|c|c|}
\hline \multirow{2}{*}{ Hormone parameter } & \multicolumn{2}{|c|}{ 11-KT } & \multicolumn{2}{|c|}{ Testosterone } \\
\hline & High exchange & Low exchange & High exchange & Low exchange \\
\hline Biofilter removal efficiency (\%) & 34.2 & 31.9 & 14.5 & 1.30 \\
\hline WRAS production (mg/day) & 0.156 & 0.128 & 0.186 & 0.025 \\
\hline Overall biomass production ( $\mu \mathrm{g} / \mathrm{kg} /$ day) & 0.36 & 0.31 & 0.43 & 0.06 \\
\hline
\end{tabular}

Table 4: Androgen production and removal characteristics within high and low exchange WRAS treatment groups.

\section{Discussion}

The major finding of this study was that, for most of the hormones measured, their rate of accumulation was not a function of WRAS exchange rate. The sole exception was T, which tended to be higher in concentration in low exchange WRAS. Differences in T accumulation between the two treatments, however, were less than the 10 -fold difference in concentration that could occur if the constituents were entirely conserved (i.e., as with sodium chloride addition) due to the 10-fold difference in WRAS flushing rate between treatments. Approximately $15 \%$ of $\mathrm{T}$ was removed across the unit processes in the high exchange WRAS, but a statistical difference in T concentration across the unit processes was not found in the low flushing treatment group. Assuming that the majority of target hormone removal was through biodegradation or sorption to suspended solids [53-55] in the fluidized sand biofilter, as opposed to volatilization in the stripping column and/or LHO, this finding suggests that $\mathrm{T}$ is slightly degradable within the biofilter, but is not as degradable as 11-KT, which demonstrated significant reduction in concentration across the unit processes. In contrast, E2 was not reduced across the unit processes, but it did accumulate in the WRAS to levels greater than found in the makeup water.

Despite the relative accumulation of $\mathrm{T}$ in low exchange WRAS, the prevalences of apparently sexually mature male salmon in the high and low exchange treatment groups were not significantly different. It is therefore unlikely (assuming some form of dose-response relationship) that water-borne $\mathrm{T}$ levels were responsible for the observed male maturation, and furthermore it remains unknown as to why such a large proportion of the study's male population matured early. As discussed earlier, variables such as lighting regime and intensity, sustained elevated water temperature in the culture environment, nutritional factors, species strain, and the accumulation of unmeasured hormone(s) or compound(s) all could have played a role, alone or in combination, with the precocious male maturation in this study, and further research is required to expand our understanding of this phenomenon. Precocious female maturation (based on external signs), while low in prevalence compared to early maturing males, was nonetheless present in both treatment groups, with higher prevalence trending towards statistical significance in the high exchange group. Again, the reason for this difference in prevalence is unknown. Given that the only measured significant difference between high and low treatment groups was the higher concentration of $\mathrm{T}$ in low exchange WRAS, it is possible that higher water-borne levels of this hormone were acting to inhibit precocious female maturation; however, several studies have shown $\mathrm{T}$ to have a stimulatory effect on early oogenesis and female maturation in coho salmon Oncorhynchus kisutch [56] and milkfish Chanos chanos [57]. If female maturation inhibition did indeed occur in the low exchange treatment group, then this requires further investigation due to the numerous environmental and physiological factors that can disrupt oogenesis and induce ovarian follicular atresia $[58,59]$ and, at present, our poor understanding of the mechanisms for regulating teleost oocyte atresia in general [60].

The mass balance results indicated that approximately 0.31 to 0.36 $\mu \mathrm{g}$ of 11-KT was produced daily for every kilogram of salmon biomass in the system. Given that 11-KT was the only measured hormone demonstrating significant removal (i.e., 32-34\%) across the WRAS unit processes, the trending of 11-KT concentration in the water recirculating system was analogous to the trending of total ammonia nitrogen (TAN) in a water recirculation system. In other words, fish produce TAN and $11-\mathrm{KT}$ in the culture tank, and microbes in the biological filter remove TAN and 11-KT from the recirculating water to the extent that the makeup water flushing rate through the system has little effect on the accumulation of TAN or 11-KT in the system. Why $11-\mathrm{KT}$, and none of the other measured hormones, was significantly removed across the unit processes is unclear; however, the reason for this observation could be related to the different physicochemical properties of the target hormones. Specifically, the octanol-water 
Citation: Good C, Davidson J, Earley RL, Lee E, Summerfelt S (2014) The Impact of Water Exchange Rate and Treatment Processes on Water-Borne Hormones in Recirculation Aquaculture Systems Containing Sexually Maturing Atlantic Salmon Salmo salar. J Aquac Res Development 5: 260. doi:10.4172/2155-9546.1000260

partition coefficient $\left(\log \mathrm{K}_{\mathrm{ow}}\right)$, a dimensionless concentration ratio used to indicate an organic compound's tendency to adsorb to sediment (i.e., the higher a compound's $\log \mathrm{K}_{\mathrm{ow}}$ value, the more likely it is to bind to organics instead of remaining in the aqueous phase) is considerably lower for 11-KT (1.92) compared to T (3.27), E2 (3.94), and P (3.67) [61] (cortisol also has a low $\log \mathrm{K}_{\mathrm{ow}}$ value (1.86; [62]); however, the data from this study did not indicate any significant differences in $\mathrm{C}$ between WRAS and makeup water, and at these concentrations no removal across the unit processes could be observed). Therefore, compared to $\mathrm{T}, \mathrm{E} 2$, and $\mathrm{P}, 11-\mathrm{KT}$ is partitioned to a greater degree in the aqueous phase, which may facilitate biodegradation during passage through the fluidized sand biofilter. By comparison, T, E2, and P are relatively more partitioned into the organic phase, and in their adsorbed state these hormones likely require longer contact time with biofilter microbes to be biodegraded; however, the study WRAS biofilters had short hydraulic retention times (approximately $5 \mathrm{~min}$ ), and therefore conditions were likely more favorable for biodegradation of compounds with low $\log \mathrm{K}_{\mathrm{ow}}$ values such as 11-KT. In examining the removal of steroid hormones from water sources, much of the published research has focused on estrogenic compounds (and other endocrine disrupting chemicals) and their fate following passage through wastewater or sewage treatment facilities $[54,63,64]$, which have far longer retention times (e.g. 10-15 days) than WRAS treatment processes. It is therefore difficult to compare the present study with previously published research in this area, and further investigation is needed to elucidate the fate of steroid hormones following relatively rapid passage through WRAS bioreactors.

This study was not able to determine a link between hormone accumulation in WRAS and the prevalence of precocious sexual maturation in Atlantic salmon, and therefore further research is required to investigate the environmental conditions that can instigate this phenomenon. Although other environmental and host factors likely contribute to early salmon maturation in WRAS, it remains possible that specific substances accumulate in WRAS water and, at particular concentration thresholds, influence maturation. Further research should focus on other soluble substances, such as maturationinducing hormone (17a,20ß-dihydroxy-4-pregnen-3-one), as well as the hormones targeted in this study, albeit with a more comprehensive (spatially and temporally) water sampling regimen.

\section{Conclusions}

Among the hormones measured, only $\mathrm{T}$ accumulated in WRAS relative to system flushing rates, although water-borne concentrations of 11-KT and E2 were also significantly higher than influent makeup water. Only $11-\mathrm{KT}$ demonstrated reduction in concentration following passage through the WRAS unit processes. The only significant difference in sexually mature fish prevalence between treatments was a higher prevalence of mature female fish in low exchange WRAS, corresponding with higher levels of T. Overall, these findings suggest that most of the measured hormones do not accumulate in WRAS (at least those comparable in design to the WRAS used in this study) relative to exchange rates, and for the most part the observed precocious sexual maturation was unrelated to WRAS exchange rate.

\section{Acknowledgement}

Our gratitude is extended to Phillip Backover, Brandon Gottsacker, and Elliot Reid for their assistance with sampling and data collection, and to Dr. Greg Weber (USDA Agricultural Research Service) for critical manuscript review. This research was supported by the USDA Agricultural Research Service under Agreement No. 59-1930-5-510. The experimental protocols and methods described are in compliance with the Animal Welfare Act (9CFR) requirements and were approved by TCFFI's Institutional Animal Care and Use Committee (IACUC). Use of trade names does not imply endorsement by the U.S. Government.

\section{References}

1. Taylor EB (1991) A review of local adaptation in Salmonidae, with special reference to Pacific and Atlantic salmon. Aquaculture 98: 185-207.

2. Fjelldal PG, Hansen T, Huang T-S (2011) Continuous light and elevated temperature can trigger maturation both during and immediately after smoltification in male Atlantic salmon (Salmo salar). Aquaculture 321: 93-100.

3. Thorpe JE (1994) Reproductive strategies in Atlantic salmon, Salmo salar L. Aquaculture Research 25: 77-87.

4. Taranger GL, Haux C, Stefansson SO, Björnsson BT, Walther BT, et al., (1998) Abrupt changes in photoperiod affect age at maturity, timing of ovulation and plasma testosterone and oestradiol-17 $\beta$ profiles in Atlantic salmon, Salmo salar. Aquaculture 162: 85-98.

5. Bromage N, Porter M, Randall C (2001) The environmental regulation of maturation in farmed finfish with special reference to the role of photoperiod and melatonin. Aquaculture 197: 63-98.

6. Taranger GL, Vikingstad E, Klenke U, Mayer I, Stefansson SO, et al., (2003) Effects of photoperiod, temperature and $\mathrm{GnRH}$ a treatment on the reproductive physiology of Atlantic salmon (Salmo salar L.) broodstock. Fish Physiology and Biochemistry 28: 403-406.

7. Vikingstad E, Andersson E, Norberg B, Mayer I, Klenke U, et al., (2008) The combined effects of temperature and $\mathrm{GnRHa}$ treatment on the final stages of sexual maturation in Atlantic salmon (Salmo salar L.) females. Fish Physiology and Biochemistry 34: 289-298.

8. Kadri S (2003) Grilse reduction and beyond: growth benefits of photoperiod manipulation in cages. Proceedings of the $2 n d$ St. Andrews Biological Station Aquaculture Workshop: Early Maturation of Atlantic salmon.

9. Alne H, Skinlo Thomassen M, Sigholt T, Berge RK, Rørvik KA (2009) Reduced sexual maturation in male post-smolt $1+$ Atlantic salmon (Salmo salar L.) by dietary tetradecylthioacetic acid. Aquaculture Research 40: 533-541.

10. Rowe DK, Thorpe JE (1990) Suppression of maturation in male Atlantic salmon (Salmo salar L.) parr by reduction in feeding and growth during spring months. Aquaculture 86: 291-313.

11. Friedland KD, Haas RE (1996) Marine post-smolt growth and age at maturity of Atlantic salmon. Journal of Fish Biology 48: 1-15

12. Duston J, Saunders RL (1999) Effect of winter food deprivation on growth and sexual maturity of Atlantic salmon (Salmo salar) in sea water. Canadian Journal of Fisheries and Aquatic Sciences 56, 201-207.

13. Wolters WR (2010) Sources of phenotypic and genetic variation for seawater growth in five North American Atlantic salmon stocks. Journal of the World Aquaculture Society 41: 421-429.

14. Klemetsen A, Amundsen PA, Dempson JB, Jonsson B, Jonsson N, et al. (2003) Atlantic salmon Salmo salar L., brown trout Salmo trutta L. and Arctic charr Salvelinus alpinus (L.): a review of aspects of their life histories. Ecology of Freshwater Fish 12: 1-59.

15. Berrill IK, Porter MJR, Smart A, Mitchell D, Bromage NR (2003) Photoperiodic effects on precocious maturation, growth and smoltification in Atlantic salmon, Salmo salar. Aquaculture 222: 239-252.

16. Skilbrei OT, Heino M (2011) Reduced daylength stimulates size-dependen precocious maturity in 0+ male Atlantic salmon parr. Aquaculture 311: 168-174.

17. Duston J, Saunders RL (1997) Life histories of Atlantic salmon altered by winter temperature and summer rearing in fresh- and sea-water. Environmental Biology of Fishes 50: 149-166.

18. McClure CA, Hammell KL, Moore M, Dohoo IR, Burnley H (2007) Risk factors for early sexual maturation in Atlantic salmon in seawater farms in New Brunswick and Nova Scotia, Canada. Aquaculture 272: 370-379.

19. Aksnes A, Gjerde B, Roald SO (1986) Biological, chemical and organoleptic changes during maturation of farmed Atlantic salmon, Salmo salar. Aquaculture 53: 7-20.

20. Johnston IA, Li X, Vieira VLA, Nickell D, Dingwall A, et al., (2006) Muscle and flesh quality traits in wild and farmed Atlantic salmon. Aquaculture 256: 323 336. 
Citation: Good C, Davidson J, Earley RL, Lee E, Summerfelt S (2014) The Impact of Water Exchange Rate and Treatment Processes on Water-Borne Hormones in Recirculation Aquaculture Systems Containing Sexually Maturing Atlantic Salmon Salmo salar. J Aquac Res Development 5 : 260. doi:10.4172/2155-9546.1000260

Page 7 of 7

21. Gjedrem T (2000) Genetic improvement of cold-water fish species. Aquaculture Research 31: 25-33.

22. Benfey TJ (1999) The physiology and behaviour of triploid fishes. Reviews in Fisheries Science 7: 39-67.

23. Hansen LP, Jacobsen JA, Lund RA. (1999) The incidence of escaped farmed Atlantic salmon, Salmo salar L., in the Faroese fishery and estimates of catches of wild salmon. ICES Journal of Marine Science 56: 200-206.

24. Schiermeier Q (2003) Fish farms' threat to salmon stocks exposed. Nature 425

25. Hansen LP, Windsor ML, Youngson AF (1997) Interactions between salmon culture and wild stocks of Atlantic salmon: The scientific and management issues. ICES Journal of Marine Science 54: 963-1225.

26. McGinnity P, Prodohl P, Ferguson A, Hynes R, O Maoileidigh N, et al., (2003) Fitness reduction and potential extinction of wild populations of Atlantic salmon, Salmo salar, as a result of interactions with escaped farm salmon. Proceedings of the Royal Society B: Biological Sciences 270: 2443-2450

27. Haya K, Burridge LE, Chang BD (2000) Environmental impact of chemical wastes produced by the salmon aquaculture industry. ICES Journal of Marine Science 58: 492-496

28. Sara G (2007) A meta-analysis on the ecological effects of aquaculture on the water column: Dissolved nutrients. Marine Environmental Research 63: 390 408

29. Johnsen BO, Jensen AJ (1994) The spread of furunculosis in salmonids in Norwegian rivers. Journal of Fish Biology 45: 47-55.

30. Naylor R, Eagle J, Smith W (2003) Salmon aquaculture in the Pacific Northwest: A global industry. Environment 45: 18-39.

31. Lillehaug A, Lunestad BT, Grave K (2003) Epidemiology of bacterial diseases in Norwegian aquaculture - a description based on antibiotic prescription data fo the ten-year period 1991 to 2000. Diseases of Aquatic Organisms 53: 115-125.

32. Davidson J, Good C, Welsh C, Brazil B, Summerfelt S (2009) Heavy metal and waste metabolite accumulation and their effect on rainbow trout performance in a replicated water reuse system operated at low or high system flushing rates. Aquacultural Engineering 41: 136-145

33. Martins CIM, Pistrin MG, Ende SSW, Eding EH, Verreth JAJ (2009) The accumulation of substances in Recirculating Aquaculture Systems (RAS) affects embryonic and larval development in common carp Cyprinus carpio. Aquaculture 291: 65-73.

34. Martins CIM, Eding EH, Verreth JAJ (2011) The effect of recirculating aquaculture systems on the concentration of heavy metals in culture water and tissues of Nile tilapia Oreochromis niloticus. Food Chemistry 126: 1001-1005.

35. Taranger GL, Carillo M, Schulz RW, Fontaine P, Zanuy S, et al., (2010) Control of puberty in farmed fish. Gen Comp Endocrinol 165: 483-515.

36. Ellis T, James JD, Stewart C, Scott AP (2004) A non-invasive stress assay based upon measurement of free cortisol released into the water by rainbow trout. Journal of Fish Biology 65: 1233-1252.

37. Kidd CE, Kidd MR, Hofmann HA (2010) Measuring multiple hormones from a single water sample using enzyme immunoassays. Gen Comp Endocrino 165: 277-285.

38. Friesen CN, Chapman LJ, Aubin-Horth, N (2012) Holding water steroid hormones in the African cichlid fish Pseudocrenilabrus multicolor victoriae. Gen Comp Endocrinol 179: 400-405.

39. Vermeirssen LM, Scott AP (1996) Excretion of free and conjugated steroids in Rainbow trout (Oncorhynchus mykiss): evidence of branchial excretion of the maturation-inducing steroid 17, 20ß-dihydroxy-4-pregnen-3-one. Gen Comp Endocrinol 101: 180-194.

40. Sorensen PW, Pinillos M, Scott AP (2005) Sexually mature male goldfish release large quantities of androstenedione into the water where it functions as a pheromone. Gen Comp Endocrinol 140: 164-175.

41. Ellis T, James JD, Scott AP (2005) Branchial release of free cortisol and melatonin by rainbow trout. Journal of Fish Biology 67: 535-540.

42. Cavaco JEB, Bogerd J, Goos H, Schulz RW (2001) Testosterone inhibits 11-ketotestosterone-induced spermatogenesis in African catfish (Clarias gariepinus). Biology of Reproduction 65: 1807-1812.
43. Schulz RW, Miura T (2002) Spermatogenesis and its endocrine regulation. Fish Physiology and Biochemistry 26: 43-56.

44. Campbell B, Dickey J, Beckman B, Young G, Pierce A, et al., (2003) Endocrine changes associated with the growth of pre-vitellogenic oocytes in coho salmon, Oncorhynchus kisutch. Fish Physiology and Biochemistry 28: 287-289.

45. Rodriguez L, Begtashi I, Zanuy S, Carrillo M (2005) Long-term exposure to continuous light inhibits precocity in European male sea bass (Dicentrarchus labrax L.): hormonal aspects. General and Comparative Endocrinology 140: $116-125$

46. Chadwick EMP, Claytor RR, Leger CE, Saunders RL (1987) Inverse correlation between ovarian development of Atlantic salmon (Salmo salar) smolts and sea age. Canadian Journal of Fisheries and Aquatic Sciences 44: 1320-1325.

47. King HR, Pankhurst NW (2003) Ovarian growth and plasma sex steroid and vitellogenin profiles during vitellogenesis in Tasmanian female Atlantic salmon (Salmo salar). Aquaculture 219: 797-813.

48. Murack PJ, Parrish J, Barry TP (2011) Effects of progesterone on sperm motility in fathead minnow (Pimephales promelas). Aquatic Toxicololgy 104: 121-125.

49. Davidson J, Good C, Welsh C, Summerfelt ST (2011) The effects of ozone and water exchange rates on water quality and rainbow trout Oncorhynchus mykiss performance in replicated water recirculating systems. Aquacultura Engineering 44: 80-96.

50. Good C, Davidson J, Welsh C, Snekvik K, Summerfelt S (2011) The effects of ozonation on performance, health, and welfare of rainbow trout Oncorhynchus mykiss in low-exchange water recirculation aquaculture systems. Aquacultural Engineering 44: 97-102.

51. Davidson J, Good C, Barrows FT, Welsh C, Kenney PB et al., (2013) Comparing the effects of feeding a grain- or a fish meal-based diet on water quality, waste production, and rainbow trout Oncorhynchus mykiss performance within low exchange water recirculating aquaculture systems. Aquacultural Engineering 52: 45-57.

52. Zar JH (1996) Biostatistical Analysis. (3rdedn), Prentice Hall.

53. Rogers H (1996) Sources, behavior, and fate of organic contaminants during sewage treatment and in sewage sludges. Science of the Total Environment 185: 3-26.

54. Onda K, Nakamura Y, Takatoh C, Miya A, Katsu Y (2003) The behavior of estrogenic substances in the biological treatment process of sewage. Water Science and Technology 47: 109-116.

55. Mansell J, Drewes JE (2004) Fate of steroidal hormones during soil-aquifer treatment. Ground Water Monitoring and Remediation 24: 94-101.

56. Forsgren KL, Young G (2012) Stage-specific effects of androgens and estradiol17 beta on the development of late primary and early secondary ovarian follicles of coho salmon (Oncorhynchus kisutch) in vitro. Biology of Reproduction 87 $1-14$.

57. Marte CL, Lawrence WC, Sherwood NM (1988) Induced gonadal maturation and rematuration in milkfish: limited success with chronic administration of testosterone and gonadotropin-releasing hormone analogues $(\mathrm{GnRH}-\mathrm{A})$. Aquaculture 74: 131-145

58. Saidapur SK (1978) Follicular atresia in the ovaries of nonmammalian vertebrates. Int Rev Cytol 54: 225-244.

59. Guraya SS (1986) The cell and molecular biology of fish oogenesis. In Monographs in Developmental Biology, Krager Publishers, Switzerland.

60. Ramezani-Fard E, Kamarudin MS, Harmin SA (2012) Endocrine control of oogenesis in teleosts. Asian Journal of Animal and Veterinary Advances 8: 205215

61. Yang Y-Y, Gray JL, Furlong ET, Davis JG, ReVello RC, et al., (2012) Steroid hormone runoff from agricultural test plots applied with municipal biosolids. Environ Sci Technol 46: 2746-2754.

62. Leszczynski DE, Schafer RM (1990) Nonspecific and metabolic interaction between steroid hormones and human plasma lipoproteins. Lipids 25: 711-718.

63. Chimchirian RF, Suri PSS, Fu H (2007) Free synthetic and natural estrogen hormones in influent and effluent of three municipal wastewater treatment plants. Water Environment Research 9: 969-974.

64. Cicek N, Londry K, Oleszkiewicz JA, Wong D, Lee Y (2007) Removal of selected natural and synthetic estrogenic compounds in a Canadian full-scale municipal wastewater treatment plant. Water Environment Research 79: 795-800. 